\title{
Electronic Resources for Teaching Ukrainian as a Second Language
}

\author{
Nataliia V. Marchenko ${ }^{1}$, Halyna I. Yuzkiv ${ }^{2}$, Iryna M. Ivanenko², \\ Olena M. Khomova ${ }^{2}$ \& Kateryna M. Yanchytska ${ }^{2}$ \\ ${ }^{1}$ Department of Adult Education, Faculty of Education and Research Management, National Pedagogical \\ Dragomanov University, Kyiv, Ukraine \\ ${ }^{2}$ Department of Ukrainian Studies, Bogomolets National Medical University, Kyiv, Ukraine \\ Correspondence: Nataliia V. Marchenko, National Pedagogical Dragomanov University, 9 Pyrogova st., Kyiv, 01601, \\ Ukraine.
}

Received: November 20, 2020

Accepted: February 4, 2021

Online Published: February 5, 2021

doi:10.5430/ijhe.v10n3p234

URL: https://doi.org/10.5430/ijhe.v10n3p234

\begin{abstract}
The article analyzes the effective electronic resources used in teaching Ukrainian as a second language. The authors highlight informational, educational, and controlling resources. Using electronic resources in the Ukrainian language teaching and learning process facilitates the development of an active vocabulary and critical thinking of the international students, lexical and linguistic competence, intensive study of phonetics, spelling, grammatical features of the language, and the diversity of the educational process. The significant effect of these resources in learning a foreign language is related to digitization and how it has affected the modern young generation, who cannot imagine their lives without varieties of gadgets. Mobile applications, which can be downloaded to any device, are designed for students to learn the lexical minimum, develop the correct pronunciation, improve their spelling and vocabulary, and practice making sentences. At the same time, the use of electronic resources when studying Ukrainian as a second language requires the students to be thoroughly self-organized and motivated. They are programmed only to reproduce a certain lexical or grammatical field, have no student-teacher or student-student feedback, aimed at checking the level of knowledge assimilation at a certain stage. Electronic resources should be used, under the control of a teacher, as a simulator for mastering the lexical minimum and grammar. These resources cannot replace communicative situations and speech cases, during which students actively use vocabulary and master speech constructions, and thus acquire lexical competence.
\end{abstract}

Keywords: Ukrainian as a second language, lexical competence, electronic resources, mobile applications, online services, training intensification

\section{Introduction}

One tendency of the modern educational space is the openness of borders for acquiring knowledge, developing professional skills. Because of academic mobility, students have the opportunity to choose higher education institutions that offer original educational programs and ensure their quality implementation. According to the state-owned enterprise InfoResources, in the academic year 2019-2020, 63,820 international students studied in Ukraine. Although many of them choose English as their language of instruction, one of the required subjects in their curriculum is Ukrainian. This is because foreigners stay in Ukraine for an average of 1 to 6 years, which is why socialization of personality, familiarity with the culture and traditions of the country, and self-realization are important.

Currently, international students face several problems when studying Ukrainian, namely: 1) insufficient classroom hours; 2) a significant percentage of the Russian speaking population of the country, and a decrease in motivation to learn the official language; 3) communication only within ethnic groups, not with native speakers, etc.

One of the effective ways to increase the cognitive interest of students in learning Ukrainian is innovative teaching technologies. They allow you quickly and effectively to develop key competencies such as communicative, country, linguistic and cultural, vocational, social. It is quite productive for teachers and students to use several electronic resources to facilitate the educational process and achieve a significant result in mastering a foreign language. 


\section{Literature Review}

Publications of V. Bykov, V. Wember, A. Gurzhia, M. Zhaldak, L. Kartashova, V. Lapinsky, N. Morse, O. Spirin, and other researchers are devoted to the problems of the use of e-learning resources in the educational process. We share the opinion of V. Lapinsky, who states that "the combination of the well-known principle of" active inclusion of all students in the educational process "with the ability to effectively manage the form and pace of submission of educational material, the volume and content of portions of educational material ("Information frames" according to the terminology adopted by some researchers), provided by modern learning tools, makes it possible to transition to the use of EDR to interactive learning" (Lapinsky, 2004). Against this background, electronic resources have become the important means of interactive and intensive learning of a foreign language, both at school and higher education institutions.

Using electronic resources by a teacher in teaching a foreign language is a very relevant topic of research for many Ukrainian and foreign scholars. D. Andreeva, O. Bigich, N. Dobrovolskaya, O. Petrova, N. Popova, I. Akavets, O. Shumsky, Neda Mohammadi, Farideh Hamidi, Vahid Ghorbani, Monica Condruz-Bacescu, Marta Gluchmanova, Meena Singhal and others explored the possibilities of using these resources when learning a foreign language. Using mobile applications in learning a non-native language has become a subject of interest for A. Demidenko, D. Medvidovskaya, T. Turchina, L. Gorbatiuk, G. Alekseeva, N. Kravchenko, T. Razumna, Ruti Gafni, Dafni Biran Achituv, Gila Joyce Rachmani, Ramya Gangaiamaran, Madhumathi Pasupathi, Bin Zou, Jiaying Li, and others. Scholars focus on theories and methods of using electronic resources when learning a foreign language.

The methodology of teaching Ukrainian as a foreign language is not yet a well-researched phenomenon in Ukrainian linguistics. The general approaches to studying the process of teaching Ukrainian as a foreign language (UMI) are covered in the studies by I. Kochan, T. Kudina, O. Turkevich, T. Sergienko, M. Tsurkan, G. Shvets, and others. Using information and communication technologies in the lessons with UIM became a subject of interest: V. Bader, I. Gryshchenko, I. Kochan, A. Kudin, T. Kudina, L. Matsko, L. Roman, and others. However, scholars focus only on specific online resources that can be used for the intensive course of the educational process. Questions regarding the ways to use mobile applications, electronic services, and printed editions during studying Ukrainian remain relevant for students.

The purpose of the article is to describe and analyze the system of electronic resources as an effective means of forming the lexical competence of international students when they study Ukrainian.

\section{Theoretical Basis of the Research}

Lexical competence plays an important role in mastering a foreign language since a sufficient vocabulary of words allows information to be exchanged within certain areas (both professional and household, personal, educational) and topics of communication. It consists in the ability "of a person to use his or her vocabulary based on lexical knowledge, and to retrieve from memory a word-standard for each specific speech task and, of course, to use well and appropriately the chosen expressions, professional terminology, etc." (Ivanova, 2014).

The basis of lexical competence is lexical skills, which are formed in three stages: mastering lexical knowledge (phonetic, graphic, spelling, grammatical, semantic, etc.), training, and direct communication. The resilience of these skills depends on the level of their automation in performing various exercises using all kinds of speech activities (listening, reading, speaking, and writing). Formed vocabulary-minimum, selection of teaching material and methods all this allows the student to master a foreign language. Considering that during the classes all kinds of speech activity should be applied, peculiarities of the combination of lexical units, linguistic and speech nuances are revealed, electronic resources become a tool of intensification of the educational process both within the audience and beyond.

Electronic resources are understood as "learning aids on digital media of any type or placed in information and telecommunication systems that are reproduced by electronic technical means and used in the educational process" (Ministry of Education and Science, Youth and Sports of Ukraine, 2012). The main aim of their use in the training of students-students of UMI is seen in the modernization and intensification of the educational process, accessibility, refinement of educational material, diversification of tasks and forms of knowledge acquisition, development of all four types of speech activity, the effective formation of linguistic and speaking skills.

Modern electronic resources can be divided into informational, educational, and controlling ones.

Educational information resources are e-learning publications that contain systematic theoretical material. These include textbooks, tutorials, dictionaries, and more. 
Electronic resources are a collection of various electronic educational services and communication tools that demonstrate the models of an object of observation.

Controlling electronic resources are electronic, standardized tasks for determining the student's educational achievement and self-control.

Using electronic resources when learning Ukrainian as a second language is justified, as it promotes:

- individualization and differentiation of learning;

- high level of identification of the material;

- self-control and reflection;

- motivation;

- audio and video speech perception;

- interactive learning;

- development of students' creativity;

- increasing vocabulary and professional communication.

Using electronic resources in teaching Ukrainian as a second language "allows, in the absence of a natural language environment, to create conditions that are as close as possible to real language communication" (Roman, 2015). Let's look at modern electronic resources that are actively used by teachers in higher education institutions to study the Ukrainian language for international students.

\section{Research Methods}

In our study, the problem of involving electronic resources in teaching Ukrainian as a second language used the following methods: analysis and synthesis of psychological and pedagogical literature to clarify the basic concepts of the study; generalization and systematization of the views of methodologists on the peculiarities of the use of various electronic resources in the formation of lexical competence of international students in the study of Ukrainian; system analysis, content analysis, the generalization of the obtained results.

\section{Results and Discussion}

\subsection{Using Electronic Learning Resources}

Electronic publications containing systematic educational material are used by students both during the practical training and in the individual work on the topic. One of the important types of electronic information resources is E-books. According to the research of O. Korbut (Corbut, 2010), the constructive elements of this type of textbook are tests, encyclopedias, problem papers, and media (creative, authorial, and non-verbal). Unfortunately, electronic textbooks for studying Ukrainian as a second language are not enough. Today, to teach Ukrainian as a second language, they are being developed in the Moodle distance learning shell. However, there are no publicly available electronic textbooks for this discipline. They are developed by a team of authors of educational institutions solely for use by their contingent of students, who are required to register in Moodle and receive access to training from the course moderator.

This type of electronic information resource, which is additional to the main textbook, was developed at the National Pedagogical Drahomanov University, Ternopil National Medical Gorbachevsky University, and others. The educational resource of the first educational institution is characterized by the presence of theoretical grammar material as Word-document, which is attached to the texts of movie dialogues, the graphic text of dialogues aimed at studying the vocabulary of the Ukrainian language and grammatical constructions, explanatory audio dictionary, translation dictionary (Ukrainian-Russian-English-Chinese), Camtasia Studio's Interactive Motion Picture Bank, exercises, control tests, additional resources. Communication between students and the moderator occurs in chat rooms or forums. Active feedback and continuous monitoring of students' knowledge lead to increased learning effectiveness (Kudin et al., 2011).

Students also use different dictionaries to help find the right word or phrase within seconds. Currently popular are "Interpretive Dictionary of Modern Ukrainian" on the portal slovnyk.net, eleven-volume "Dictionary of the Ukrainian language" on the portal sum.in.ua, "Dictionaries of Ukraine" and others. These editions feature an active vocabulary of the Ukrainian language, as well as terminology, dialecticism, and neologisms.

A precious resource for studying by foreigners of the Ukrainian language is the resource of the Ukrainian Language and Information Fund of the NAS of Ukraine "Dictionaries of Ukraine", which combines spelling dictionary, 
dictionary of synonyms and antonyms, phraseological dictionary, and the function of word translation. The user can easily learn about the peculiarities of spelling, and pronunciation of over 261 thousand words of the Ukrainian literary language, to obtain information about the pronunciation of the desired word in all grammatical meanings (hyphens, numbers, persons, etc.), its synonyms, and antonyms, interpretation of phraseologies.

Using different dictionaries in the study of Ukrainian by international students aims, first, to teach them to independently find the interpretation of the word and, accordingly, to properly construct with it a phrase, a sentence, and to express their own opinion.

\subsection{Using Electronic Teaching Resources}

Digital learning resources can be divided online: websites and mobile applications that students can use to learn the language, and services used by teachers to prepare interactive exercises that promote the development of practical skills, the application of theoretical knowledge of phonetics, morphology, grammar, syntax, syntax. It should be noted that there are a lot of websites and mobile applications for learning Ukrainian. Conventionally, they can be divided into those aimed at learning the elementary level language and those aimed at improving and deepening linguistic knowledge. We analyze online resources (websites and mobile applications) aimed at developing the language and language skills of students who have recently started learning Ukrainian.

Mobile applications facilitate access to Ukrainian at a convenient time and place for the student. Usually, they contain vocabulary, pictures, and words, various exercises to test knowledge. «Mobile devices provide plenty of resources to develop the listening skill of the learners who can be exposed to authentic material like live streams, (...) songs, radio, listening to (...) news» (Ramya \& Madhumathi, 2017). The most productive applications include:

- Learn Ukrainian from Duolingo.com - an application that allows you to learn vocabulary, selected according to common topics. The student has the opportunity to familiarize himself with the pronunciation of the word, memorize it, use it several times in a word combination by translating, for example, into English, to listen to an utterance or sentence in Ukrainian, and to choose from several offered lexical units. A condition for learning each topic that combines several lessons is to provide the correct answers to all the suggested tasks. The error in the answers requires repeated exercise, which contributes to the constant training and consolidation of the material that caused the difficulties. The so-called test completion level is coming to an end. About 2,000 words can be learned in one course. This application is aimed at forming a student's vocabulary, developing the ability to correctly, structured to formulate sentences and hearing, to write dictation. However, the major drawback of Duolingo.com to learn Ukrainian is that the application is not aimed at developing students' communication skills, and therefore the language barrier remains unmatched. This is further confirmed by the fact that the mobile application can be used in conjunction with classroom training.

- goethe-verlag.com/book2 - a mobile application that brings together 100 structured lessons, clearly divided into topics. Before starting the course, an application user has the opportunity to determine their language proficiency.

To do this, you need to pass a small test that includes word translation, misspellings, hearing, and word and phrase reproduction, and more. Each lesson contains audio files made by native speakers of the Ukrainian language, dialogues that are close to real-life situations, and tests for learning the subject matter (fill in the gaps in words and sentences, construct sentences correctly). Alphabet, vocabulary, and language games are available to the user: vocabulary, matching antonyms for nouns, adjectives, and verbs, solving crossword puzzles, and more. The app focuses more on word reading and writing. The resource is aimed at students who are learning a language from the ground up, as well as those who want to replicate and consolidate their knowledge.

- FunEasyLearn English - a mobile application containing fifteen topics and subtopics. The resource is more focused on the play form of learning the lexical minimum and contains three levels: initial (1,000 words), medium (2,000 words), and high (3,000 words). «Gamification is a very important feature in performing repeating tasks, which can be very boring. Learning a new language can be so. Therefore, playing with the words and competing versus others can be very encouraging, thus stimulating the learning process» (Ruti Gafni, 2017). The user has the opportunity to test the learned words by performing various exercises: word-combining, selecting the right word, spelling, etc. The application is aimed at listening, writing, and reading words. Its major disadvantage is that the resource is not focused on forming a user's ability correctly to spell words and formulate sentences. Similar to the FunEasyLearn Ukrainian app is Internet Polyglot and Learning and Play English.

Thus, the main purpose of using mobile applications in learning Ukrainian as a second language is to master the lexical minimum of common words, to spell and write them correctly. Only a few applications are intended to develop the ability of users correctly to spell words and formulate sentences. Mobile app listening is only used for voice and word processing. With this in mind, a major drawback of mobile applications is the lack of text-handling, listening, reading, 
and translation. These resources are only an aid in learning a foreign language, as they cannot form and develop students' communication skills.

Much more educational material is offered by various author's websites for studying Ukrainian as a second language. These include:

- Ukrainian lessons - a site that contains free podcasts and articles for learning the Ukrainian language by foreigners. The lessons comprise four parts: dialogue or text in Ukrainian, a detailed explanation of several short topics in English, oral exercises, and information on Ukrainian culture. Audio lessons are provided once a week. Learners can also find a dictionary, grammar rules with examples given, the most common phrases and songs of Ukrainian performers (lyrics in Ukrainian and English, and videos) on the site.

The site allows foreigners to get acquainted with the Ukrainian culture, traditions, outstanding people, and descriptions of the most beautiful corners of the country together with the study of the language. This resource is, to a greater extent, aimed at developing the user's communication skills.

- Life hacks in Ukrainian - TV project of UA: First TV channel, which can be found on YouTube. Videos are about rules of emphasis, which is very important for foreigners, as they often misspell words, and linguistic conversations related to holiday greetings and thanksgiving rules. Currently, 14 videos are available, but the selection is constantly updated. Please note that the video of the project can be used for educational purposes for students who have mastered the Ukrainian language at a sufficiently high level and want to improve their knowledge.

- Speak Ukraine is an educational portal created by the Association for Innovative and Digital Education and the Academy of Skills. Here you can get about 100 interesting lessons, write 25 texts on commonly used topics, read dialogues and do various exercises. The portal offers topics according to levels A1-A2 and B1-B2, which testifies to a well-developed scheme of memorizing words, and subsequently word combinations and sentences, reproduction of dialogues daily.

Therefore, mobile applications and web portals are only ancillary resources for learning Ukrainian as a foreign language. They are not able to cover all types of speech, but at the same time, they contribute to the effective formation of vocabulary, spelling skills, the ability to build sentences correctly and engage in dialogues on common topics. In the process of studying Ukrainian, foreigners should not use only mobile applications or services only. They should complement each other. In our opinion, there is no perfect resource for today, so students should draw on information, supplement it and test their knowledge by performing differentiated exercises, listening to the audio, or watching videos from one or another of the teacher's educational portals.

In addition to numerous mobile applications and learning sites, which are useful for intensive study of the Ukrainian language by foreigners, teachers use certain network services in their work that allow diversifying the educational process. Let's focus on some of the online services:

- learningapps.org - a service that allows you to create exercises online. It is a kind of constructor for the development of interactive tasks, the fulfillment of which contributes to the development of cognitive interests of students and students. The service contains a collection of didactic exercises and templates for creating your own (Fig. 1). 

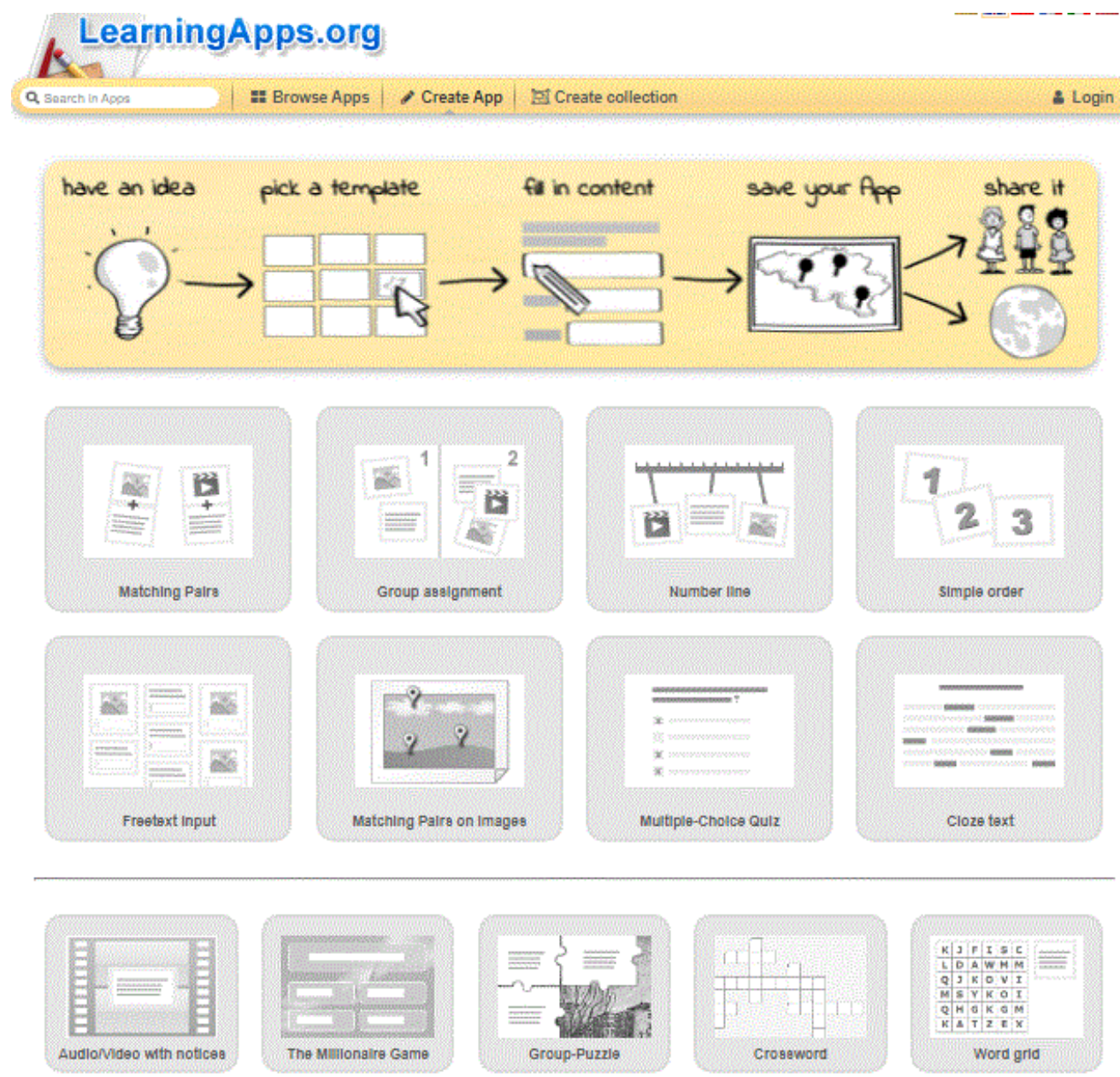

Figure 1. Template for designing exercises

Besides the usual exercises that can be viewed on mobile applications and copyright websites, the service allows you to create tasks using audio, video content, and questions, to perform tasks (such as in the "Horse Racing" format) for both students and students, group grammatical phenomena, and more. Teacher's use of learningapps.org contributes to the rapid, detailed, and deep development of practical skills in the use of knowledge in the form of play.

- Tagul - an online service that allows you to create word clouds from the text entered by the user. This service facilitates the visualization of information and the student's focus on tasks that relate only to the words in the picture.

For example, a teacher may offer students:

- write a sentence or story using as many words as possible from the cloud;

- find words that belong to a particular part of the language or with an accent on the first syllable

- to study vocabulary, for example, adjectives (Fig. 2);

- Create your cloud puzzles and more.

Thus, word clouds can be directed both to the acquisition of linguistic knowledge, repetition of the studied material, and the development of communicative abilities of international students. 


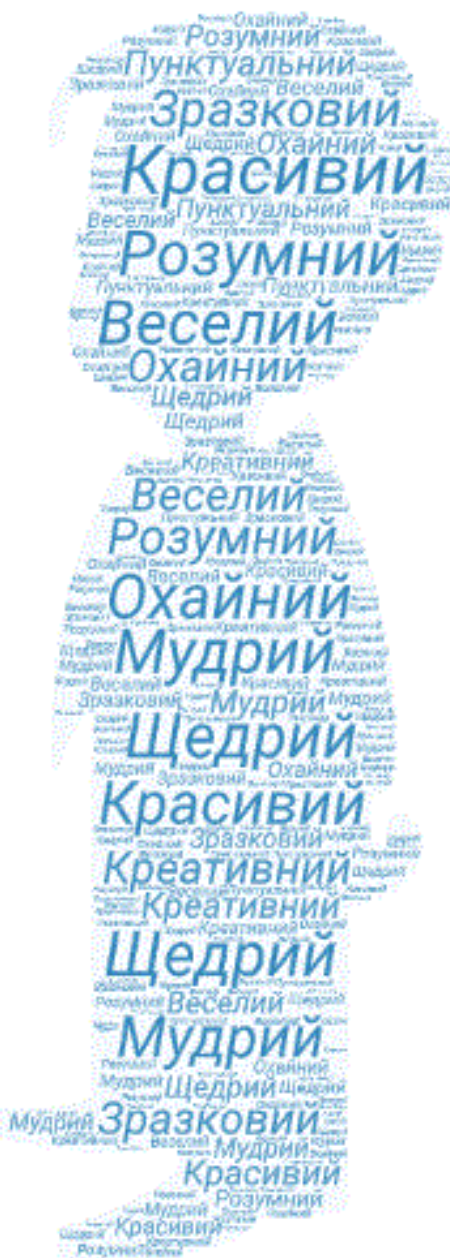

Figure 2. A cloud of words for learning adjectives denoting human traits

- Loupe - a service designed to create image collages. When learning the language, "collage - is seen as a visual aid, a methodical technique that involves a consistent extension of the lexical background of a key concept and thus creates a visual and content-schematic image of the concept under consideration" (Lutsenko, 2018) You can use image collages when studying any topic. For example, when studying the theme "Vegetables and Fruits" the poster contains images of the most popular products, and the teacher shows and pronounces their name, students repeat. Subsequently, it is suggested to answer the question "What is a fruit or a vegetable?" or "Name the fruit pictured", "What do you buy at the store?", "What is your favorite vegetable?" etc. During the study of the theme "Family" you can ask students to create collages of photos of their family, and during their demonstration to tell about each of its members by the algorithm: name, date of birth, age, profession, hobby, tell about character traits, etc. Collage services for learning a foreign language are aimed at building vocabulary and developing communication skills. Reception of collage promotes the construction of "visual logical supports, creates prerequisites for the development of abstract thinking, and the skills of students' independent work" (Lutsenko, 2018).

- Coggle.it or Mindomo - services that allow you to create mental maps - schemes that visualize certain information are used at all stages of working with lexical or grammatical material. The main requirement when creating a mental map is to have a central image and a keyword on each line. An example of an application of this service is the author's development, presented in Fig. 3. Illustrated theoretical material on the subject of "Noun" can be seen in demonstration mode by gradually expanding branches, processing information, performing exercises, and systematizing knowledge. 


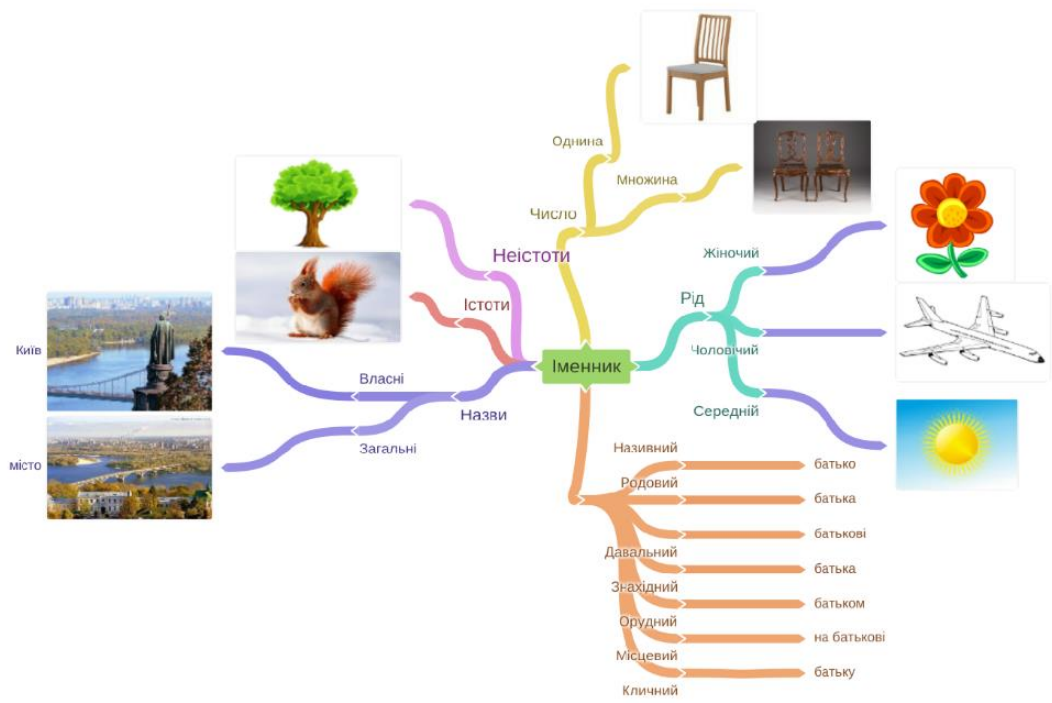

Figure 3. The mental map on the theme "Noun"

- Padlet - a service that allows you to download, save, and work with students and files. This kind of interactive whiteboard can be used to:

- "organization of group work during the "brainstorming", generalization and systematization of knowledge, reflection;

- to place educational information or tasks for its search;

- to organize joint homework;

- as a place for project ideas and discussion;

- as a tool for organizing co-operative student activity both in the classroom and after-school hours" (Morkvyan \& Khmil 2016).

The service is very user-friendly, as the teacher can create an unlimited number of virtual boards (for example, on a specific topic), attach photos, video and audio files, create publications, supplement or remove information, give students access to their designs, and get homework completed. The advantage of Padlet is that the service allows you to organize the information and have constant access to it. The teacher can use his own experience at any time for rational and productive use of teaching time, the illustration of theoretical material, listening or watching the video, during working on a text, etc. In this way, Padlet saves participants time and supplies as they are submitted online.

- Google provides a wide range of services. For example, in the process of learning Ukrainian as a second language, use Classroom, which is designed to work on any mobile device that gives students greater mobility when completing assignments. This "interactive service will allow the teacher when choosing a task to choose to share the document or automatically create a copy for each student; see who completed the task and who did not; give feedback and ask students in real-time, both in and out of the classroom" (Morozova, 2019). Google is also used to create questionnaires, test online and evaluate work, etc.

Therefore, there are quite a few helpful online services that facilitate students' online learning. When studying Ukrainian as a second language, the emphasis is on subconsciously memorizing information, so it is important to use the above services with textbook work and alternation of different types of speech activities.

\subsection{Using Electronic Tools for Controlling}

One of the compulsory elements of the educational process is the assessment of students' knowledge, skills, and competencies. Nowadays tests in Ukraine become very popular during the control of knowledge at a certain stage of the subject's study. Online services that can provide this include Kahoot and the Master Test. Their main purpose is to create a sufficient number of subject teachers, give them the right to set the algorithm for analyzing the test results, view the achievements of each user, actively use audio and video material, and more. Cloud testing technologies allow you to create the optimal information and educational environment.

Kahoot's online service allows you to create interactive learning games that consist of a series of questions and multiple answers. This form of testing is of interest to students who can complete online assignments, both independently and in 
teams, using any mobile device connected to the Internet (Fig. 4.). The time for their implementation is set by the teacher. At the end of the game, students can observe the rating of the competition, determine the winner, and discuss issues where mistakes are made.

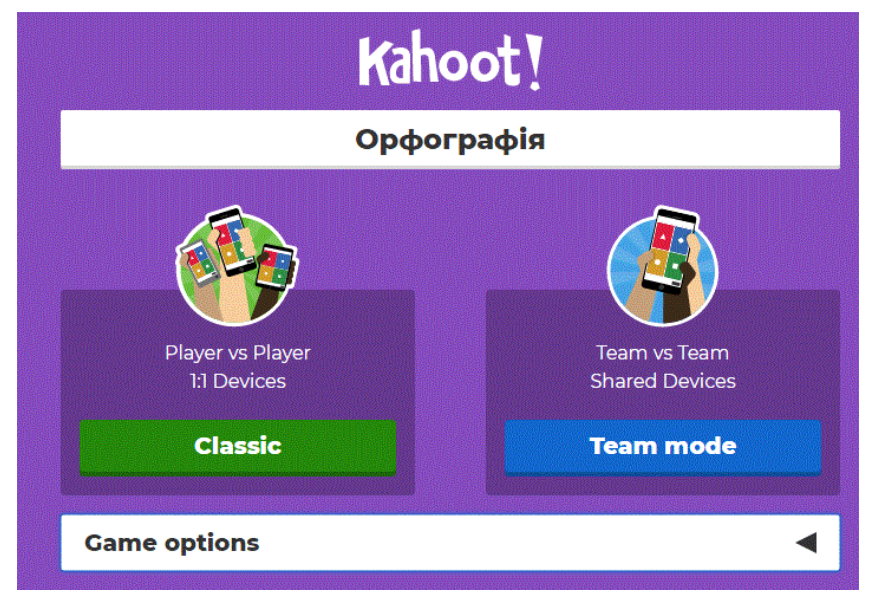

Figure 4. Quiz «Orthography»

The service offers the user several forms for creating test tasks: Quiz, Poll, and Slide. The quiz combines various forms of test-taking that develop critical thinking:

- Quiz itself - creating multiple-choice questions, of which only one is correct. Used to test knowledge, skills, and knowledge of a particular topic;

- True or False - choosing the right answer between the two suggested (true/false). It can be used, for example, when studying spelling, watching videos, or listening to audio to determine students' understanding of information;

- Open-ended - teacher-created questions for writing endings of words. It is especially important to apply this form of testing in the consolidation and control of knowledge of writing endings of personal verbs of the present, past, future tenses, nouns, phrases, etc.;

- Puzzle - a system of tasks that are aimed at placing the answers in a specific sequence.

Creating a quiz, the teacher can combine different forms of Quiz, which will help to attract different types of speech and knowledge control, identify gaps in mastering the language.

In addition to creating test tasks, the service also helps to start and engage in discussion by creating an Idea Presentation and Analysis (Poll), it also enables the teacher to create online and present slides.

Similar to the Kahoot online service is the Master Test.

The capabilities of the Master Test include:

- creating an unlimited number of test questions online;

- use in questions of video, audio, photo, etc.;

- sending tests to students by e-mail;

- an indication of the date by which the test is to be performed;

- automatic verification and detailed report on the results of its implementation.

Therefore, the use of online tests and programs to create them when teaching students of Ukrainian as a second language is an effective tool for diagnosing the acquisition of basic material, correction of knowledge, the objectivity of evaluation of student's achievements, etc.

\subsection{The Results of the Experiment}

The above-mentioned electronic resources were used by the students of Bogomolets National Medical University in the course of studying Ukrainian as a second language. We combined traditional and electronic resources according to the topic of one or another class. Note that classroom use of electronic resources during the study of the Ukrainian language by international students took $30 \%$ of the lesson time (20-25 minutes). 
Mobile applications (Learn Ukrainian from Duolingo.com, FunEasyLearn English, goetheverlag.com/book2) are used for mastering thematic vocabulary and speech constructions, as they offer to listen to the correct pronunciation of words, writing them, and doing exercises. Students use these applications as a simulator after the teacher has spoken and discussed the lexical minimum of the topic, as well as during homework to reinforce what they learned in class.

Resources of the Ukrainian lessons site contain short lessons on various topics. We used them during demonstrating grammar rules and introducing international students to Ukrainian culture.

The resources of the Speak Ukraine website (https://ukr.lingva.ua/) were used to read many thematic dialogues and then independently composing and studying their lexical constructions, and afterwards reproducing them by the students in the classroom.

Materials of the TV project Life hacks in Ukrainian were used as educational demonstration material during the study of grammar. The short videos contain dialogues, demonstrating the use of grammar rules in the direct communication of native speakers.

When studying Ukrainian as a second language, we used several online services to develop new exercises, as none of the textbooks at the moment have enough exercises for foreigners to learn the Ukrainian language.

Such services as learningapps.org, Tagul, Loupe, Popplet, Padlet, facilitated the development of various types of exercises. This contributed to the use of the students' lexico-grammatical skills.

The final stage of studying each module was accompanied by test tasks, which were developed with the help of such programs as Kahoot and the Master Test. Varied formulation of tasks allowed us to analyze the level of mastering of Ukrainian vocabulary and grammar.

To confirm our hypothesis that electronic resources help to increase the level of students' proficiency in Ukrainian, we conducted an experimental study with the participation of the control and experimental groups.

Training in the control groups was conducted using the usual means of training: the use of textbooks, cards, texts, and more. In the experimental groups, blended learning was used. The focus was on the use of e-learning resources described in the previous sections of the article.

The effectiveness of the use of electronic resources has been experimentally confirmed. The study, which was conducted in the 2018-2019 academic year, involved 100 international students of the first year of the National Medical University full-time study: 50 students belonged to the control group and 50 to the experimental group. Due to the active use of electronic resources during the study of Ukrainian as a second language, the hypothesis of increasing students' acquisition of lexical competence in the experimental group was confirmed (Fig. 5).

Diagnosis of the level of students' lexical competence formation in the course of studying Ukrainian as a second language was performed according to the level of vocabulary, communicative and grammatical components. They were divided by levels according to the number of correctly completed tasks: high $(90 \%-100 \%)$, sufficient $(71 \%-89 \%)$, medium $(50 \%-70 \%)$, and low $(0 \%-49 \%)$

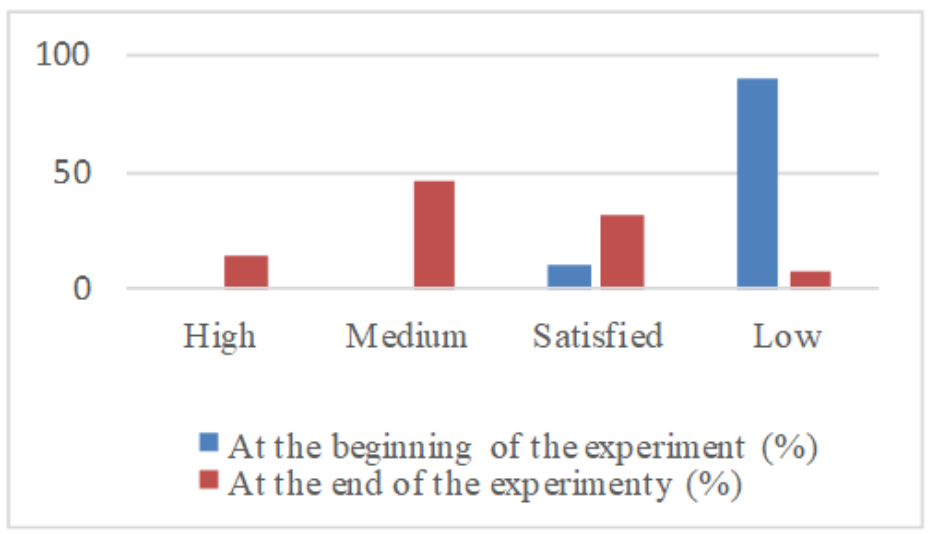

Figure 5. Dynamic of mastery of lexical competence

The results of the study show a significant increase in mastery of lexical competence, in percentage terms, at sufficient, medium, and high levels. The indicators confirm the dynamics of the process under study. We observed an increase in lexical competence in the experimental group at the end of the experiment at a high level of $14 \%$, at the average level - 
$46 \%$, at a sufficient level - $22 \%$, and the low-level indicators changed from $90 \%$ to $8 \%$, which is a difference of $82 \%$ (Table 1).

Table 1. The results of the study conducted in the experimental group

\begin{tabular}{ccccccc}
\hline Levels & \multicolumn{2}{c}{$\begin{array}{c}\text { At the beginning } \\
\text { The number of } \\
\text { students }\end{array}$} & $\%$ & $\begin{array}{c}\text { At the end } \\
\text { The number of } \\
\text { students }\end{array}$ & $\%$ & \multicolumn{2}{c}{$\begin{array}{c}\text { Dynamic } \\
\text { The number of } \\
\text { students }\end{array}$} & $\%$ \\
\hline High & 0 & 0 & 7 & 14 & 7 & 14 \\
Medium & 0 & 0 & 23 & 46 & 23 & 46 \\
Satisfied & 5 & 10 & 16 & 32 & 11 & 22 \\
Low & 45 & 90 & 4 & 8 & -37 & -82 \\
\hline
\end{tabular}

The indicators of the control group also show positive dynamics: average level - $40 \%$, sufficient level - from $26 \%$ to $48 \%$, and low level from $74 \%$ to $12 \%$ (Table 2). However, the analysis of quantitative indicators shows the lack of mastery of students' lexical competence at a high level and somewhat less dynamic compared to the experimental group.

Table 2. Results of the study conducted in the control group

\begin{tabular}{cccccc}
\hline \multicolumn{2}{c}{ At the beginning } & \multicolumn{2}{c}{ At the end } & \multicolumn{2}{c}{ Dynamic } \\
\hline $\begin{array}{c}\text { The number of } \\
\text { students }\end{array}$ & $\%$ & $\begin{array}{c}\text { The number } \\
\text { of students }\end{array}$ & $\%$ & $\begin{array}{c}\text { The number } \\
\text { of students }\end{array}$ & $\%$ \\
0 & 0 & 0 & 0 & 0 & 0 \\
0 & 0 & 20 & 40 & 20 & 40 \\
13 & 26 & 24 & 48 & 11 & 22 \\
37 & 74 & 6 & 12 & -31 & -62 \\
\hline
\end{tabular}

Thus, analysis of the dynamics of the study results confirms that the use of electronic resources in the experimental group has significantly increased the number of students with high, medium, and sufficient levels of lexical competence at this stage of learning Ukrainian as a second language.

\section{Conclusions}

Therefore, the use of blended learning in learning Ukrainian as a second language contributes to the rapid acquisition of lexical competence. The possibilities of electronic resources are the intensification of the educational process, diversification of forms of work in class, the performance of tasks in a convenient place and free time, refinement of educational material, motivation, self-reflection, self-control, etc.

Nowadays, electronic resources are actively used by both students and teachers to achieve better learning outcomes. As the modern world is full of various information and communication technologies, participants in the educational process of love use all digital devices, which are constantly at hand, to gain new knowledge.

Particularly popular with international students are mobile applications for learning Ukrainian (Learn Ukrainian, FunEasyLearn Ukrainian, goethe-verlag.com/book2) and websites (Ukrainian lessons, Lifehacks in Ukrainian, Speak Ukraine). They allow you to form a sufficient vocabulary, develop communication, spelling, grammar skills, and more.

Electronic resources allow the teacher to easily develop interactive exercises using various services, such as learningapps.org, Tagul, Loupe, Popplet, Mindomo, etc., create tests, control students' level of mastery of acquired knowledge, and lexical competence.

This study does not exhaust all aspects related to the use of electronic resources when learning Ukrainian as a second language. Further research is seen in the theoretical and practical analysis of the organization of the educational process of learning Ukrainian as a second language based on the information and educational environment.

At the same time, the use of electronic resources when studying Ukrainian as a second language requires from the student proper self-organization and motivation. They are programmed only to reproduce a certain lexical or grammatical field, have no student-teacher or student-student feedback, aimed at checking the level of knowledge assimilation at a certain stage. Electronic resources should be used, under the control of a teacher, as a simulator for mastering the lexical minimum and grammar. These resources cannot replace communicative situations and speech 
cases, during which students actively use vocabulary and master speech constructions, and thus acquire lexical competence.

\section{References}

Lapinsky, V. (2004). Electronic educational resources - didactic requirements and classification. Retrieved from http://lib.iitta.gov.ua/2004/

Ivanova, O. O. (2014). Information and communication technologies in the process of formation of professionally oriented lexical competence. Advanced Education, 1, 21-29. https://doi.org/10.20535/2410-8286.29264

Ministry of Education and Science, Youth and Sports of Ukraine. (01.10.2012). Order No. 1060. On approval of the Regulations on Electronic Educational Resources. Retrieved from https://zakon.rada.gov.ua/laws/show/z1695-12

Roman, L. A. (2015). Information technology as an innovation in teaching Ukrainian as a foreign language. Science and Education a New Dimension. Pedagogy and Psychology, III (22), 45, 42-45.

Corbut, O. G. (2010). An electronic textbook as an element of the educational environment, materials of $V$ International scientific-practical. conf. Modern methods of teaching a foreign language of vocational guidance in higher education. Kyiv. 24-38.

Kudin, A. P., Kudin, T. M., Matsko, L. I., Zhabyev, G. V., \& Zinyuk, V. V. (2011). Quality of provision of educational services in distance learning. Naukovyi chasopys NPU imeni M. P. Drahomanova. Seriia 5. Pedahohichni nauky: realii ta perspektyvy, 28, 121-128.

Ramya, G., \& Madhumathi, P. (2017). Review on Use of Mobile Apps for Language Learning. International Journal of Applied Engineering Research, 12, no. 21, 11242-11251.

Ruti Gafni, Dafni Biran Achituv, \& Gila Joyce Rachmani (2017). Learning Foreign Languages Using Mobile Applications. Journal of Informational Technology Education: Research, 16, 301-317. https://doi.org/10.28945/3855

Lutsenko, G. M. (2018). The use of collage as a means of visualization when learning a foreign language. Retrieved from https://academia.in.ua/content/vykorystannia-kolazhu-yak-zasobu-naochnosti-pry-vyvchenni-inozemnoi-movy

Morkvyan, I. V., \& Khmil, N. A. (2016). Technique of using virtual interactive Padlet board in the educational process. Retrieved from http://osnova.com.ua/items/item-november-2016/index_3.html

Morozova, O. G. (2019). Use Google for Education services as a learning management system to shape students' creative personality. Retrieved from https://vseosvita.ua/library/vikoristanna-servisiv-google-for-education-dla-formuvanna-tvorcoi-osobistosti-ucni v-133565.html.

\section{Copyrights}

Copyright for this article is retained by the author(s), with first publication rights granted to the journal.

This is an open-access article distributed under the terms and conditions of the Creative Commons Attribution license (http://creativecommons.org/licenses/by/4.0/). 